\title{
Indigenous Knowledge in Mundum and Suptulung
}

\section{Shanti Devi Rai*}

\begin{abstract}
The dominance of formal education over the indigenous education along with the language and culture has been a pressing issue in almost all cultures of the world. The Nepalese education system is also largely influenced by the western education system. So, it is inevitable that Nepalese students too are influenced by the western education. Rai community is one of 125 indigenous groups having rich indigenous knowledge. Particularly, they have vocational education of the food security that transforms the knowledge through the cultural practices, which is close to nature and thus a unique one. The significance of the food security means survival for the whole year. Mundumic education focuses on the survival in nature and to reduction of poverty. However, such indigenous type of cultural activities as part of education have not been recognized and put into priority in the government's curriculum. This is an example of a missing link of such cultural heritage in our curriculum. Therefore, I propose here to explain a typical Binayo Movie thematically having indigeneity in its content suitable for inclusion in national curriculum. This Movie is a key to establish the Mundum and Suptulung identity within this community contributing to indigenous identity for the future generations. Thus, this article explores some significant aspects of Mundumic cultural education which helps conserve indigenous knowledge on the one hand, and on the other, reduce poverty through indigenous skills of food production and security.
\end{abstract}

Keywords: indigenous knowledge, Mundum, Suptulung, food security, Sakela

* Mrs. Shanti Devi Rai is a PhD Scholar at Graduate School of Education, Tribhuvan University. Email: shantidevi2026@gmail.com. 


\section{Introduction}

This article aims at figuring out useful and effective teaching and learning contents, which are one of the most important necessities of national educational system. Teachers in the system have a determining role in training such pupils in the mentioned fields. A school is a place where new ideas germinate; roots strike and grow tall and sturdy. It is a unique space, which covers the entire universe of knowledge. It is a place where creative minds converge, interact with each other and construct visions of new realities. Established notions of truth are challenged in the pursuit of knowledge. To be able to do all this, getting help from experienced teachers can be very useful and effective, while indigenous education system differs in paradigmatically. Indigenous education is reconfirmed by the indigenous philosophy. In Nepal's context according to Rana (2018) among the 125 indigenous groups, 123 languages are spoken but only some languages have their own script and spoken scriptures. Among them, Kirat and Kirat Rai are such indigenous groups having their education system guided by Mundum.

Educators and policy makers have long recognized the central role that education can play in creating a more sustainable and equitable world (cf. Acharya and Robinson, 2019). Yet the current system of mainstream higher education has not prepared learners sufficiently to graduate with the capabilities or motivation to shape and create a future that is life sustaining. While indigenous people do not have access to formal education in their own language, they transmit their knowledge as education verbally from generation to generation.

For the indigenous knowledge owners, the government does not show any interest in acknowledging in spite of the indigenous people's own education system. Undoubtedly, indigenous education is related with the spiritual culture, e.g., Sakela is a ritual cultural name, which is mainly about the food security system and process. Jiri, Mafongoya and Chivenge (2015) argue that local knowledge is concerned with the emerging climate change. These knowledge systems are transmitted and reconnected by every generation for good health and food security.

Additionally, food security means all security such as ecological, physical, and mental. The Kirat Rai people renew the relation with the Mang (God) twice every year Dhirinam and Chhirinam through Sakela celebration. They start this cultural celebration by venerating in Suptulung. Up to four days, 
they worship the Suptulung at every house by elder, some special rites are performed by Mangpa/Nakchho/Nachhung/Yadangba. Finally, on the fifth day, they go to Sakela with Mangpa and ask for the good health and the food security by chanting the Rishya. They humbly request whatever in the earth and sky with the Sakela Mang by performing the silli (a kind of traditional dance allowed to all children and elders) in round shape for their well-being. This silli act as a farming process, are imitation of animal, birds, and everything else that are used in livelihood. The meaning of that imitation is to respect all nature and natural things as well remember the process of work, agriculture, help each other, and respect equality. These acts are performed in the sense of food security. If food is sufficient, every nature, creature will be good and enhance livelihood in order is the main objective of the Sakela Dhirinam and Chhirinam.

Mundum's knowledge and education is perceived by people as the value of Sakela and the food security. Its example is innate in Binayo movie that describes how Mundum and Suptulung are at the center of the Kirat Rai people. Only a few documents and sources are available on the Mundumic knowledge and education system. In alarming rate, the people and the society are losing its significance and precious knowledge gradually. Here I propose to describe some Mundumic knowledge and the value of Suptulung. From the 'Binayo' movie new generations of the Kirat Rai people can understand their native culture. They recognize and realize what and how their worldview is. The people cannot buy the cultural identity with money. Thus, as a reference for readers, I describe the Binayo movie.

The Mundumic knowledge and education are encompassed in very few elderly people. In the movie, one can explore beautiful knowledge and wisdom. Indigenous people have different worldviews about the universe. Their indigenous knowledge belongs to the spiritual world. Nakata (2002) expresses that indigenous knowledge is holistic, grounded, powerless, incapable, ineffective, and culturally massive. Mundumic knowledge does not have excess to exposure in any mass media visibly. Mundum's worldviews are different from other indigenous worldviews.

Presently, the Mundumic worldview, knowledge, and education are in critical phase of endangerment. It is very necessary to preserve the indigenous paradigm of valuable knowledge of Mundum and Suptulug. With this existing situation within a couple of decades, the Mundum and Suptulung cannot remain as a cultural identity of the Kirat Rai people. They are losing their identity along with culture and language. 
This is our responsibility to preserve this cultural heritage to continue cultural diversity of the nation. Otherwise, our succeeding generation's life will end in cultural disaster. Culture and identity are most important for human beings. It makes them humans, independent and self-determining. Many people are fighting for the identity in the world today. As an example, the Kirat and Kirat Rai identity and culture have well been expressed in Binayo Movie. This movie works as a small window for Mundum and Suptulung.

According to World Bank's (Apr 02, 2019) updated review, there are approximately 370 million Indigenous Peoples (IPs) worldwide in over 90 countries. There are 5000 different groups and daily one hundred fifty thousand people are dying together with their culture. Indigenous cultures are diminishing day by day due to only verbal transmission and colonization. Instead, indigenous people are still alive enjoying and living their own culture. They learn from ritual and cultural activities by looking at their elders' performance.

\section{Statement of the problem}

Among the indigenous groups, the Kirat Rai is one of them. They have different world views of education. The Kirat Rai elders educate their children through the cultural demonstration, ritual practice that are connected with the food security, inhabitant, clothing and the irrigation.

This education system is guided by the Mundum. Mundum is their philosophy. What they are here now is due to Mundum. Mundum is the storehouse of the educational knowledge that belongs to humans since origin. This knowledge officially does practice by the Suptulung. Suptulung and the Mundum are two sides of a coin, meaning mutual interdependence. Hegemony of the formal education the Mundumic education and the educational value of the Suptulung is on the verge of extinction. The students who become part of the Mundumic education are having more challenge to adapt to the formal education system. They are confused because the home language, education and the school education are totally different. For this reason, many Mundumic students lose the opportunity to go to school for the formal education.

\section{Objective of the study}

This article explores the Mundum worldviews on transmission of indigenous education system including the food security. 


\section{Significance of the study}

This study focuses on the Mundhumic education system as well as the knowledge transformation system that is needed to improve the inclusive education or equity education. In addition, Mundumic education system has continued from the primitive time in the form of oral tradition. This educational knowledge may help to enhance the effective classroom teaching learning.

This study provides the relevant information and contents for the policy makers of education in government. This research provides insights to the study which would be useful to formulate the appropriate policy of Mundumic education to all stakeholders. Furthermore, the study can be used as a reference for other researchers for further study.

\section{Methods}

In the process of writing this paper, I used the qualitative research design as Denzin \& Licoln (2000) have focused on the interpretation of subject matter with the multiple way. I followed indigenous research methods during this study (Tuhiwai, 1999). They do justice to indigenous knowledge. I selected the participants by employing purposive sampling (Etikan, Musa, \& Alkassim, 2016). Particularly, I interviewed the three Mundum experts and reviewed the Binayo Movie. I used the in-depth interview. An unstructured interview was conducted because this interview helped the participants to be comfortable and deeply described the story telling method as (Kovach, 2010) conversational method. And I grounded the analysis and interpretation as said Creswell (2003) and (Creswell \& Creswell, 2017).

This study is limited to the Mundum experts and the visual document of the Binayo movie. The primary sources are Mundum experts and the secondary sources are written documents.

\section{Finding and discussion}

\section{Indigenous worldview of Mundum and Suptulung in education system}

Mundum's knowledge is related with the earth system, social system, and interaction with the environment. Moreover, Ajayi and Mafongoya (2017) note that indigenous education derives from the daily activities of people for survival with nature and animal world. Mundumic education belongs 
to the nature and agriculture system. This system might be dynamic, can adapt suitable education system based on ecology and necessity.

Indigenous knowledge and education are dependent on environment and self-governing. Education system exists in Mundum and Suptulung. People equally get respect as a teacher or student. There is no hierarchy as in formal education. Knowledge and education are transmitted from one generation to another generation. Some elder people do not want to go the hospital yet. This means that they do not believe in the formal education system. They believe only on the Mundum education in which they believe the Suptulung is their place for pilgrimage.

They do not want to let go the Suptulung across the sea. Such type of value is still among the Mundumic elder people. This shows that the Mundumic knowledge, education developed by the particular land, environment, and ecology for survival. It is very unique and useful collectively and individually. From elder to children can survive in any geographical area. Mundum education teaches to converse with death, interacts with environment and keeps rational relation with nature. It is related with the spirituality of culture.

Knowledge and education can be transmitted and renewed by cultural demonstration seasonally. Every person can think and use his/her knowledge in livelihood independently. However, to survive globally local indigenous knowledge needs to be preserved as in written form. Many NGOs and INGOs are working and planning to bring out such type of knowledge in curriculum all over the world as well as in Nepal. The international seminar (Caribbean, 2019) expresses indigenous knowledge to be incorporated into the education system and polices that provide the learning opportunity for indigenous people in order to restore social justice.

Additionally, in Latin America socio-political dialogues have taken place for the intermingling and the development of indigenous knowledge as well as linguistics in education system. Diversity of indigenous knowledge brings the beautiful combination in education system. However, the undocumented indigenous knowledge is in crisis as well as Mundum education system. Bhattachan (2008) points out that the general practice restricts the mother tongue education up to grade five for most of the mother tongue community. Rapacha (2013) argues for advocacy of inclusive curriculum and education. The government has recognized only a limited indigenous knowledge that can be incorporated in the mainstream education (Acharya, Jere, and 
Robinson-Pant, 2019). These arguments reaffirm that researcher, intellectual people and education organizations are attracted towards the indigenous education system. Moreover, indigenous people also do not want to lose the native cultural education. They are willing to learn them and willing to hand over the education of their own culture for their future generation. They are also worried about their children bearing conflicts in education system between formal vs. informal. Many indigenous students are in depression due to indigenous education system and mainstream education system. Some are in very difficult situation too. They are in confusion. As a result, $90 \%$ indigenous students are far from the state's mainstream formal education (Rai, 2020).

Many indigenous children drop out from schools due to their cultural missing link. The act of the teaching learning situation is discriminatory because knowingly unknowingly bad example always come from the indigenous activities or word and good example from the privileged side. Branhardt and Kawagley (2008) express that as a group of American students are not offered educational opportunities, they routinely face deteriorating school facilities, under paid teachers, weak curricula, discriminatory treatment, and out dated learning tools. This situation is pre-existing all over the world on indigenous people. Similar situation applies for the Mundumic people of Nepal.

According to Rana (2018),"Up to primary school the government has fixed the mother tongue education policy; however there lack native teachers and its implementation has remained ineffective for all the indigenous people in the context of Nepal. One of its reasons is that the content of book in mother tongues is translated from Nepali." This experience shows that the education delivery culture also should be changed, but such action is a great challenge.

\section{Indigenous food security, diverse cultural education, renew and knowledge transmission}

Indigenous culture is not grown by pre-plan; it is developed by society's daily activities to fulfill the basic requirements of people. Traditional customs, dresses, art morality, behavior, attitude, and the ritual rites are the sources of indigenous knowledge or local knowledge. It serves as the purpose of socio-economic factors, techniques, ideology as a result it reflects the identity of the society (Du Plessis and Raza, 2004). It is a fact that human kind as indigenous people have diverse techniques of food security as well as cultural rites. 
Food security system is a kind of culture and this knowledge is perceived through the activities and the cultural rites for continuity. Food is very important for life on earth. In the beginning, the Kirat Rai ancestors had done much struggle for survival in and with the nature. Before the development of science and technology, indigenous people had developed their sense and awareness about food, however they had not succeeded in all cases. Because not all types of food obviously are edible, some are harmful too and nowadays too. We hear news from radio, television, newspapers and social network about eating wild mushrooms and consumers' last breath.

However, today one cannot imagine how they sustain and develop the food security system. In October 16, 1945, Quebec City, Canada had established the Food and Agriculture Organization (FAO). Through this organization awareness has been raised for food security as well as recognized indigenous knowledge. In this sense the Kirat and Kirat Rai people, worshipping in the Mundumic Suptulung follow the Sakela ritual for food security. They have different ideology for the food security. One of them is to celebrate it twice a year in the Suptulung wishing food security. They trust on nature, time and then the calendar date and day.

When crane birds fly towards the mountain, they celebrate Dhirinam (Ubhauli). Since the primitive age African people as well as all the world's indigenous people used the indigenous knowledge for food security and the purpose of basic needs of society (Chiwanza, Musingafi and Mupa, 2013). Dhirinam (Ubhauli), in the context of food security and the whole society's prosperity, well-being, good environment, sufficient water, good health of all nature, fauna and flora, peace, protect from evil soul, avoid all kind of disease, unwanted things, illness, of the year for the purpose they celebrate is called Sakela.

The activities are performed by the Mangpa/Nakchho/Nachhung/Yadangba ('priest' can be s/he) and also, he or she can perform Sakela but they should be allowed and blessed from the Mang (god) through dreams. Gorjestain (2000) notes that indigenous knowledge system used for the local food security as well as human security, animal security and for important decision of the local society. Food security brings prosperity to people.

In a year, they can span their life smoothly. Nature remains in chronological order. The ecological system maintains in the healthy way. During the four days of Dhirinam, Mangpa/Nakchho/Nachhung/Yadangba and every household's elder people offer to ancestor for food security. It is their main 
festival as well. In this festival, they remember the entire ancestor those who get the place in the Suptulung. The Suptulung is venerated with the local liquors of six months made from the herbal leaf and Bajra. After finishing the Dhirinam, they cook the millet-beer for the next six months is called Chhirinam (Udhauli). When the crane-birds return down towards the sea then they celebrate Chirinam.

They offer all the new grains in the Suptulung before consumption. If they consume the new grains especially new ginger and paddy, they will bear the unwanted things in the whole year. Thus, they are very careful to their children also. This is the system in the Kirat Rai community about their food security. As FAO (2009) cited in LWF Nepal and Right to Food National Network Nepal with support from Thematic Alliance Members (2017), food security exists in "all people, at all times, have physical, social and economic access to sufficient, safe and nutritious food, which meets their dietary needs and food preferences for an active and healthy life". Particularly, the metaphor of Sakela is food security. This knowledge transmitted by the activities of culture to their new generation. In the Kirat Rai community, knowledge transmission is performed through the cultural rites verbally from generation to generation.

Dhirinam and Chhirinam include in Sakela meant for cultural rite of food security. In Dhirinam celebration offering of seeds for farming and ask blessing for all-natural entities which remain in between sky and the earth and Chhirinam celebration offering the virtual grain at first to their ancestor then can utilize as food. Through this system people are aware somehow about food preservation for the whole year. It means that they should not finish consuming their food before the whole year is over. That is why, they maintain the balanced diet thus avoiding hunger. Insufficient food brings mental and psychological problems for balanced life and challenges to survival. According to Mhache (2018), diverse indigenous people have diverse indigenous knowledge for food security in the world. It is developed by the geography, individual thoughts, and based on needs.

Some groups of indigenous people use sun heat, some other fire near the hearth and some other use open place under the roof, where air can pass easily and gradually. The Kirat Rai community also preserves food differently. They respect the food by celebrating and offering to the Suptulung. Souls are allowed to remain in the Suptulung in their beliefs and practices after natural death. Such pure souls are called the good souls like god; bad souls cannot reside in the Suptulung. 
Through Mundum, the Mangpa/Nakchho/Nachhung/Yadangba can converse with the soul. Each time the good soul wanders around the household people like a guardian angel. The good souls protect the community members from evil and save from the undesirable happenings. Good souls offer the peace and fortune forever. Such souls provide them sufficient food as well as other things, if they follow the Mundumic rules and regulations. If they do not follow the Mundumic ways of life, they definitely have disaster in their livelihood. The Mundumic knowledge is the reflection of ancestor's life experience, which belongs to particular land, water, plants, trees, rock, fauna and flora, animal, birds and circumstances.

For this reason, indigenous knowledge, affects the food security system although this system in this community is as cultural celebration. Food security means sufficient nutritious food for all urban and rural areas for the future too (Khumbane, 2004). The Kirat Rai community takes more care for the future than the present. Mundum speaks about the future and predicts for tomorrow.

In Dhirinam, worshippers ask about future happenings regarding good or bad times, about disease and sufferings to be avoided. They come to know the bountiful types of food crops, fruits' predictions. They celebrate Sopuiya on the first day of Sakela or Dhirinam for talking about sickness or illness during the whole year. Sopuiya means all sickness and bad fortune are put into the water thus washed away through the water. After four days' celebration of Dhirinam, they do silli (dance) in the house-yard of people.

All the relatives and guestsalsogo toevery household. Daughtersand brotherin-laws are main guests of every household. Anyhow, married daughters in this celebration should participate in maternal house. At the end of the celebration, they ask the blessings and the chari (Unnako saha 'bountifulness of crops') by dancing silli with Mangpa/Nakchho/Nachhung/Yadangba and other elder people around of Suptulung with the indigenous instrument Jhyamta/Chamakhi/Pulu/Har and the Jhyamta/Chamakhi/Pulu/Har (drum and cymbal). The Mangpa/Nakchho/Nachhung/Yadangba explains all information what has been given by ancestors or good souls and people follow the same rule throughout the year. According the given rule, it will be less bountiful; lifestyle system breaks down and should bear the whole year painfully. Food security implies that every time nutritious food available and help to keep it healthy lifestyle (Food, 2003). Diverse indigenous groups have diverse food security system means much beneficial. Different ideas can help us survive according to geography as well as climatic situations. 


\section{Indigenous agricultural system as education}

One of the primitive races of Nepal is the Kirat Rai people, who belong to indigenous groups guided by the Mundum and Suptulung. According to the census of 2011, the total number of Kirat Rai people is 620,004 (CBS, 2011). Some representative characteristics of characters as an example in Binayo movie are described here based on internal migration and differences of geographical situations.

The Kirat and Kirat Rai people suppose the farming system systematically developed by Raichhakule-a male character in the movie. He was an orphan and he does not have enough food. During this time, he hunted a bird and found some millet and paddy into the gizzard of a dove. He thought to sow the grain not to be harmful while doing so. Raichhacule thus sows the grain in the field. Since then, farming started systematically. Such type of myth is still narrated to the new generation in the community but his representative name is varying more than fifteen in different linguistic groups. Similar type of stories and myths exist in every indigenous group. However, nowadays these stories and myths are vanishing gradually. The Binayo Movie works to reconnect that knowledge. With this film many cultural education, knowledge, and beliefs have been revived.

In my experience and discourse of Binayo movie in the society, many audiences about $97 \%$ have learned the value of Mundum as well Suptulung in the Kirat and Kirat Rai community. Among such audiences 65\% have repeatedly watched the movie and remember the myth or story to share to their sons and daughters. Storytelling and songs are one of the mediums of knowledge transmission to their future generation. Mezirow (1996, p.162) as cited in (Taylor, 2017) "learning is understood as the process of using a prior interpretation to construct a new or a revised interpretation of the meaning of one's experience in order to guide future action." This story is already famous in the Kirat society but the ways of interpretation are different. The movie Binayo has constructed a consistent story based on all varieties of the same story.

The movie has portrayed indigenous knowledge about the Kirat Rai community and their rituals. The detail activities associated are shown in the movie. The movie has well documented the Kirat Rai community and their traditions. This movie has included the diversity of languages and their perspective. The characters of the movie are the same as the Kirat people claim it to be. This movie raises awareness about the endangered 
tradition and culture of the Kirat people. The emotional connections of the siblings are also shown in the movie. Despite the separation at a young age, they come together as one family in the end and live together sharing all the memories.

The film seems to be the beginning of agricultural age and other traditional natural aspects, having important message about the tradition of having a Suptulung to the people watching the movie in far off lands and the importance of conducting all the activities in the Suptulung. This film has a role of educating cultural knowledge to the teenagers and how they should do to continue the tradition from endangerment as the Kirat people are comparatively meagre in population. To those Kirat people, who do not follow the Mundum, it also raises awareness that lets them know the cultural practices of their community as it is necessary for all Kirat people to know about their own Mundum religion.

\section{Conclusion}

Culture is one of the most important factors to develop a just society and quality education. In the absence of cultural value, people cannot develop knowledge. Thus, responsible citizens and organizations must reorganize the significance of indigenous cultural values. Education has been the base of every developmental effort worldwide. Along with educational factor, indigenous knowledge is also an important factor of education. Mundum has independent worldview. From human perspective, Mundum guides them and Suptulung is their center of pilgrim or holy place. Without the Suptulung, the Mundum cannot perform or they cannot conduct any ritual rites. Thus, the Suptulung is precious for the Mundum and the Kirat Rai people. Knowledge and education whether visible or invisible have power transmitted from the Suptulung. It makes them stable and independent. Suptulung protects them from disaster and evil eyes providing them prosperity or abundance according to Mundum. Thus, at the first place they provide a parity of cultural values then education. From such culture, they learn whatever they need for livelihood, e.g., food security. Every household's special women give the parity of food security, which means well-being of everything throughout the whole year.

This education helps students and scholars gain knowledge about different cultures and their tradition. The Kirat Rai cultures also have interesting and unique ideas about human evolution, sociology, civilization and knowledge. The population of the Kirat community is comparatively lesser than other 
religions. The movie Binayo has focused and portrayed the Kirat culture and traditions uniquely. It has also given educational values to the viewers and also has played an important role to raise awareness. The movie is an interesting documentary that the viewers can enjoy with being informed alongside the story in the movie, which focuses on the basic components of the Kirat community. Nonetheless, indigenous culture is vanishing day by day due to verbal transmission only and global colonization. It is the responsibility of the new generation to keep up with the traditions of the indigenous knowledge, skills and religions. In addition, this is only possible by educating teenagers and rewarding scholars through fellowships since Kiratism is also an indigenous religion.

\section{References}

Acharya, S., Jere, C. M. \& Robinson-Pant, A. (2019). Indigenous adult women, learning and social justice: Challenging deficit discourses in the current policy environment. Studies in the Education of Adults, 1-12.

Ajayi, O. \& Mafongoya, P. (2017). Indigenous knowledge systems and climate change management in Africa. CTA.

Barnhardt, R. \& Kawagley, A. O. (2008). Indigenous knowledge systems and education 1. Yearbook of the National Society for the Study of Education, 107(1), 223-241.

Bhattachan, K. (2008). Indigenous peoples and minorities in Nepal. Nepal Federation of Indigenous Nationalities. Retrieved on Nov, 25, 2009.

Caribbean, U. O. (2019). Indigenous knowledge in education policies in Latin America: Experiences for revitalizing indigenous languages and cultures. UNESCO . Retieved on $10^{\text {th }}$ May, 2019 http://www.unesco.org/new/en/santiago/education/inclusiveeducation/international-seminar-indigenous-knowledge-in-education-policies-inlatin-america/.

Chemjong, I. S. (1967). History and culture of the Kirat people. Phidim,Nepal: Tumenhang.

Chiwanza, K., Musingafi, C. C., \& Mupa, P. (2013). Challenges in preserving indigenous knowledge systems: Learning from past experiences. Information and Knowledge Management, 3, pp. 19-25.

Cohn, R. (1981). The shape of sacred space:Four biblical studies. Studies in religion.

Collins, R. B. (2002). Sacred sites and religious freedom on government land. U.Pa,J.Const.L, $5,241$.

Creswell, J. W. (2003). Research design: qualitative. Quantitative, and mixed methods.

Creswell, J. W. \& Creswell, J. D. (2017). Research design: Qualitative, quantitative, and mixed methods approaches. California: Sage publications.

Denzin, N. K. \& Lincoln, Y. S. (2011). The Sage handbook of qualitative research. (Y. S. Lincoln, \& N. K. Denzin, Eds.) New Delhi: SAGE.

Diawuo, F. \& Issuifu, A. K. (2015). Exploring the African traditional belief system, source conservation and management in Ghana. The Journal of Pan African Studies, 8(9), 115-131.

Du Plessis, H. \& Raza, G. (2004). Indigenous culture as a knowledge system. Tydskrif vir letterkunde, 41(2), 85-98. 
Eliade, M. (1959). The sacred and the profane: The nature of religion (Vol. 81). Houghton Mifflin Harcourt.

Etikan, I., Musa, S. A. \& Alkassim, R. S. (2016). Comparison of convenience sampling and purposive sampling. American Journal of Theoretical and Applied Statistics, 5(1), 1-4.

Food, F. A. (2003). Agriculture Organization. Gender and Access to Land, FAO Land Tenure Studies, 4.

Grieves, V. (2009). Aboriginal spirituality: Aboriginal philosophy, the basis of Aboriginal social and emotional wellbeing (Vol. 9). Darwin: Cooperative Research Centre for Aboriginal Health.

Jiri, O., Mafongoya, P. \& Chivenge, P. (2015). Smallholder farmer perceptions on climate change and variability: A predisposition for their subsequent adaptation strategies. Journal of Earth Science \& Climatic Change, 6(5), 1-7.

Kovach, M. (2010). Convernational method in indigenous research. First People Child $\mathcal{E}$ Family Review, 5(1), 40-48.

Mankiller, W. (2009). Cultural Survival Quarterly Magazine. Retrieved from https://www. culturalsurvival.org/publications/cultural-survival-quarterly/being-indigenous21st-century.

McDougal, C. (1979). The Kulung Rai: study in kinship and marriage exchange. Kathmandu: Ratna Pustak Bhandar.

Mhache, E. P. (2018). The contribution of Indigenous Knowledge Systems (IKS) on food security in Mbokomu ward, Kilimanjaro Region, Tanzania. African Journal of Environmental Science and Technology, 12(3), 96-105.

Nakata, M. (2002). Indigenous knowledge and the cultural interface: Underlying issues at the intersection of knowledge and information systems. IFLA Journal, 28(5-6), 281-291.

Nicoletti, M. (2004). Shamanic solitudes: Ecstasy, madness and spirit possession in the Nepal Himalayas. Kathmandu : Vajra Publication and Ev-K2-CNR Publications.

Nicoletti, M. (2004). Shamanic solitudes: ecstasy, madness and spirit possession in the Nepal Himalayas. Kathmandu : Vajra Publication.

Pinstrup-Andersen, P. (2009). Food security: Definition and measurement. Food Security, 1(1), 5-7.

Rai, S. D. (2020). Suptulung as indigenous knowledge of Kira Rai people. Siddhajyoti Interdisciplinary Journal (SIJ), 1, 139-147.

Rana, K. (2018). Retention of English language tension in multilingual communities of Nepal: A review of teachers' narratives. Journal of NELTA, 23(1-2), 40-53.

Rapacha, L.-S. (2013). Inclusive curriculum in Nepal's context: Crossing the border. International Journal of Interdisciplinary Studies, 1(1), 85-102.

Simmins, G. (2008). Sacred spaces and sacred places. Riga,Lativa: VDM Verlag.

Taylor, E. W. (2017). Transformative learning theory. In Transformative learning meets bildung (pp. 17-29). Leiden, Netherlands: Brill Sense.

Tuhiwai, S. L. (1999). Decolonizing methodologies: Research and Indigenous Peoples. London: Zed Books.

Was, C. (2017, January). Holy place-sacred space - area of transcendence. Quart, 46(4), 4469. 